\title{
Experimental investigation on flank wear and tool life, cost analysis and mathematical model in turning hardened steel using coated carbide inserts
}

\author{
Ashok Kumar Sahoo ${ }^{a^{*}}$ and Bidyadhar Sahoo ${ }^{b}$
}

${ }^{a}$ School of Mechanical Engineering, KIIT University, Bhubaneswar-24, Odisha, India

${ }^{b}$ Department of Mechanical Engineering, IGIT, Sarang, Odisha, India

\section{H R O N I C L E A B S T R A C T}

Article history:

Received March 162013

Received in revised format

May 92013

Accepted May 92013

Available online

May 152013

Keywords:

Flank wear

Tool life

Hard turning

Coated carbide

ANOVA

Regression

\begin{abstract}
Turning hardened component with PCBN and ceramic inserts have been extensively used recently and replaces traditional grinding operation. The use of inexpensive multilayer coated carbide insert in hard turning is lacking and hence there is a need to investigate the potential and applicability of such tools in turning hardened steels. An attempt has been made in this paper to have a study on turning hardened AISI 4340 steel $(47 \pm 1$ HRC) using coated carbide inserts (TiN/TiCN/ $\left./ \mathrm{Al}_{2} \mathrm{O}_{3} / \mathrm{ZrCN}\right)$ under dry environment. The aim is to assess the tool life of inserts and evolution of flank wear with successive machining time. From experimental investigations, the gradual growth of flank wear for multilayer coated insert indicates steady machining without any premature tool failure by chipping or fracturing. Abrasion is found to be the dominant wear mechanisms in hard turning. Tool life of multilayer coated carbide inserts has been found to be 31 minute and machining cost per part is Rs.3.64 only under parametric conditions chosen i.e. $v=90$ $\mathrm{m} / \mathrm{min}, \mathrm{f}=0.05 \mathrm{~mm} / \mathrm{rev}$ and $\mathrm{d}=0.5 \mathrm{~mm}$. The mathematical model shows high determination coefficient, $\mathrm{R}^{2}(99 \%)$ and fits the actual data well. The predicted flank wear has been found to lie very close to the experimental value at $95 \%$ confidence level. This shows the potential and effectiveness of multilayer coated carbide insert used in hard turning applications.
\end{abstract}

\section{Introduction}

Hard Machining is the machining of materials that have hardness values over $45 \mathrm{RC}$. Workpiece materials are typically used and suitable for hard machining operations including heat-treated steels. Manufacturing industries are continually challenged to reduce machining cost, enhance quality and minimize setup times to remain competitive. Due to pressing demands of surface quality and dimensional accuracy, finishing operations of hardened work pieces are usually produced by traditional grinding method. The sequential steps to manufacture hardened components involves forming, annealing, rough machining of unhardened steel, heat treating the steel to the required hardness and finish machining to the required dimensional accuracy.

* Corresponding author. Tel: +6746540805

E-mail: aklala72@gmail.com (A.K.Sahoo)

(C) 2013 Growing Science Ltd. All rights reserved.

doi: $10.5267 / \mathrm{j} . \mathrm{ijiec} .2013 .05 .003$ 
Grinding involves expensive machinery, long manufacturing cycles, costly support equipment, and lengthy setup times. In addition, grinding possesses material removal rate lower than the machining process. Both environmental factors like disposal of coolant and swarf and economic concerns due to high cost of grinding are accelerating the replacement of grinding by hard machining, which can be successfully performed in dry cutting condition. Hard turning eliminates the series of operations steps, reduces the cycle time, costs, and elimination of coolant and improves the productivity (Tönshoff et al., 1995; Tönshoff et al., 2000). Higher material removal rate and relatively low tool cost compared to the grinding are some of the economical and ecological benefits.

Sahin (2009) indicated that the CBN cutting tool showed the best performance than that of ceramic based cutting tool during turning AISI 52100 steel (659HV). Cutting speed exerted the greatest effect on the tool wear, followed by the hardness of cutting tool, lastly the feed rate. In an experimental study accomplished by Lalwani et al. (2008), depth of cut was found to be the dominant contributor to the feed force in turning hardened MDN250 steel (50 HRC) using coated ceramic tool. In the thrust force and cutting force, feed rate and depth of cut contributed more. Horng et al. (2008) studied the machinability evaluation of austenitic Hadfield steel in the hard turning using A12O3/TiC mixed ceramics tool $(70 \% \mathrm{Al} 2 \mathrm{O} 3,30 \% \mathrm{TiC})$ for flank wear and surface roughness. Cutting speed and interaction effect of feed rate with nose radius of tool was the main factors influencing the flank wear. For surface roughness, the most influencing factor was the cutting speed and the tool corner radius.

Aggarwala et al. (2008) investigated the power consumption in hard turning of AISI P-20 tool steel (32-36 HRC) using TiN coated carbide insert with Taguchi's and RSM technique. Cryogenic environment was the most significant factor in minimizing power consumption followed by cutting speed and depth of cut. The effects of feed rate and nose radius were found to be insignificant. RSM technique was found to be better than Taguchi's method. Ozel and Karpat (2005) developed regression and ANN models in finish hard turning of AISI H13 steel for surface roughness and tool wear. Decrease in the feed rate, better was the surface roughness but slightly faster tool wear development. Increasing cutting speed resulted in significant increase in tool wear development but resulted in better surface roughness. Increase in the workpiece hardness resulted in better surface roughness with higher tool wear.

More et al. (2006) investigated CBN-TiN composite-coated carbide inserts for hard turning of AISI 4340 steel (53 HRC). The flank wear was mainly due to abrasion in the machining of hardened AISI 4340 steel. The crater wear of the CBN-TiN coated inserts was found to be less than that of the PCBN inserts because of the lubricity of TiN layer. The coated inserts produced good surface finish and yielded a tool life of $18 \mathrm{~min}$. The machining cost reduction was found for cBN-TiN coated carbide tools compared to PCBN tools. Sahoo and Sahoo (2011) developed mathematical model for flank wear and surface roughness in hard turning using coated carbide insert and correlated for its significance. It shows the high correlation between the experimental and predicted values. From ANOVA table, it is evident that, feed is the significant factor affecting surface roughness followed by cutting speed. For flank wear, cutting speed is the most significant factor followed by depth of cut. Feed is found to be insignificant for flank wear.

Sahoo and sahoo (2011) investigated the performance of coated carbide insert in machining D2 steel using response surface methodology and high correlation was established with this proposed methodology. Tamizharasan et al. (2006) proposed that as an alternative to grinding, the hard turning produced better surface finish, lower flank wear rate and high material removal on the selected crank pin material by low content CBN tool. Sahin and Motorcu (2008) developed surface roughness model in machining hardened steel with cubic boron nitride cutting tool through response surface methodology. The results indicate that the feed rate was found out to be dominant factor on the surface roughness. A good agreement between the predicted and experimental surface roughness was observed within reasonable limit. Yallese et al. (2005) investigate the effect of cutting parameters on ceramic and $\mathrm{CBN}$ tool wear in the hard turning of $\mathrm{X} 200 \mathrm{Cr} 12$ steel $(60 \mathrm{HRC})$. The results indicate that the 
comparison span for both tool materials is limited to a speed of $180 \mathrm{~m} / \mathrm{min}$ at which catastrophic ceramic cutting edge collapse took place. The tool life ratio rose from 4.37 to 17.14 when the cutting speed evolved from 90 to $180 \mathrm{~m} / \mathrm{min}$ in favour of CBN, which resisted up to a cutting speed of 350 $\mathrm{m} / \mathrm{min}$. The feed rate effect on roughness $(\mathrm{mm})$ is satisfactorily predicted by a power model deduced from experimental data and is compared with a theoretical model.

Cutting performance of PCBN and ceramic tool materials has been extensively investigated in hard turning and improved performance has been noticed from literature survey. It is very interesting to note that, very little work have been reported to study the performance of inexpensive multilayer coated carbide insert in hard turning. Definitely, research is needed to justify the potential of multilayer coated carbide inserts in hard turning due to economical reasons. Thus, an attempt has been taken in the present work to have a study on hard turning of AISI 4340 steel ( $47 \pm 1$ HRC) using multilayer coated carbide inserts (TiN/TiCN/Al $\left.{ }_{2} \mathrm{O}_{3} / \mathrm{ZrCN}\right)$ and assess the tool life under dry environment in context of evolution of flank wear. The machining cost per part has also been carried out for economical study. The mathematical model has been developed for prediction of flank wear using regression analysis and correlated for its significance.

\section{Experimental details}

\subsection{Workpiece}

The workpieces is taken in the form of cylindrical bar of diameter $45 \mathrm{~mm}, 200 \mathrm{~mm}$ length AISI 4340 medium carbon low alloy high strength steel. The workpiece is heated to austenizing temperature of $920^{\circ} \mathrm{C}$ around 30 minute and quenched in oil. Then, tempering is carried out for 2 hours followed by air cooling. The hardness of bar after heat treatment is found to be $47 \pm 1$ HRC. AISI 4340 steel is typically used in the manufacturing of automobile and machine tool parts.

\subsection{Machine tool}

The machine tool used was a high rigid $\mathrm{CNC}$ lathe (AMS, India) having maximum spindle speed of $3500 \mathrm{rpm}$ and power of $16 \mathrm{KW}$ with Sinumeric controller.

\subsection{Cutting inserts}

In tests, multilayer $\mathrm{CVD}$ coated carbide insert ( $\left.\mathrm{TiN} / \mathrm{TiCN} / \mathrm{Al}_{2} \mathrm{O}_{3} / \mathrm{ZrCN}\right)$ of ISO designation CNMG $120408\left(80^{\circ}\right.$ diamond shaped insert) mounted on a PCLNR2525 M12 tool holder has been used for experimentation to assess the tool life. The insert with tool holder has the nose radius of $0.8 \mathrm{~mm}$ and major cutting edge angle or approach angle of $95^{\circ}$ with back rake angle of $-6^{0}$ respectively.

\subsection{Measurement and cutting conditions}

Flank wear has been measured by using Nikon profile projector (V10 AD) at tool nose radius portion. The images of worn inserts are captured by stereo zoom microscope (radical instrument). The criteria of flank wear is taken as $\mathrm{VBc}=0.3 \mathrm{~mm}$. Cutting condition has been taken for experimentation such as cutting speed (v) of $90 \mathrm{~m} / \mathrm{min}$, feed (f) of $0.05 \mathrm{~mm} / \mathrm{rev}$ and depth of cut (d) of $0.5 \mathrm{~mm}$ respectively. The experiment has been conducted with successive machining time to assess the tool life under dry cutting conditions.

\section{Results and discussions}

\subsection{Flank wear and tool life assessment}

The progression of flank wear with successive machining time has been shown in Fig. 1 for $\mathrm{ZrCN}$ multilayer coated carbide inserts at their parametric conditions. The tool life is assessed when the flank wear exceeds the limit of $0.3 \mathrm{~mm}$. 


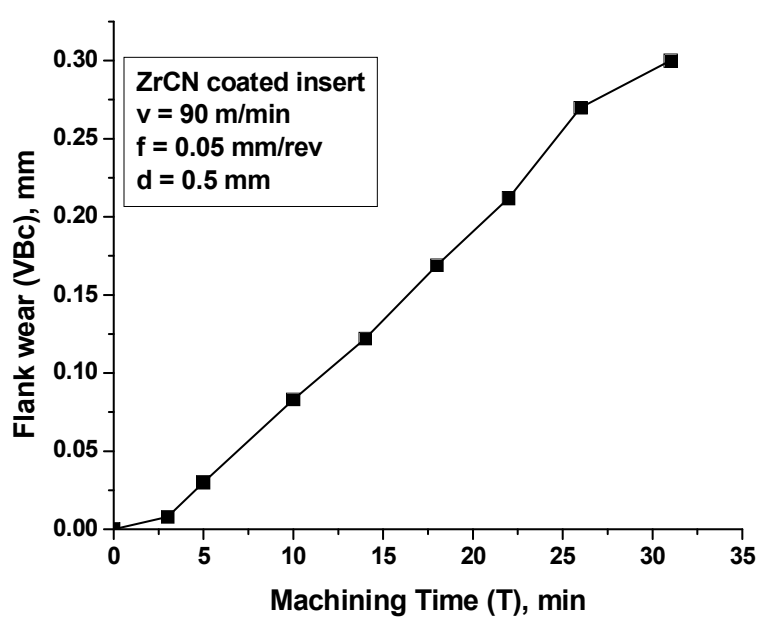

Fig. 1. Progressions of flank wear with machining time

It has been observed that the flank wear evolution was steady without any premature failure and remains within recommended limit of $0.3 \mathrm{~mm}$ when cutting is performed with multilayer coated carbide insert under dry conditions. The flank wear value increases with machining time. Images of worn out inserts after expiry of tool life (VBc approaches to $0.3 \mathrm{~mm}$ ) has been shown in Fig. 2.

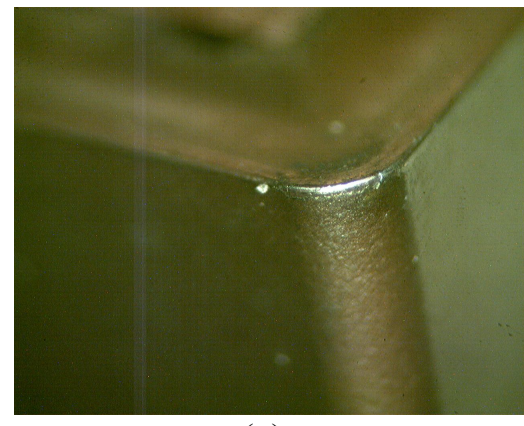

(a)

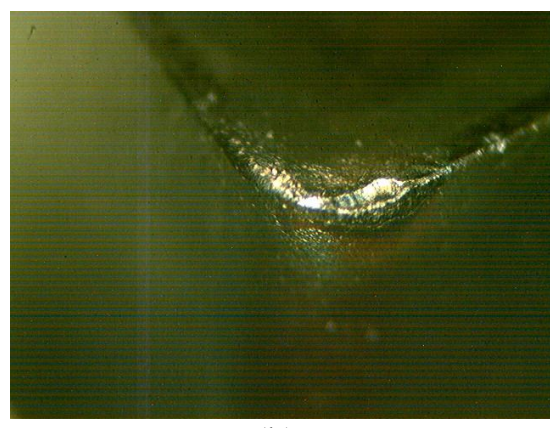

(b)

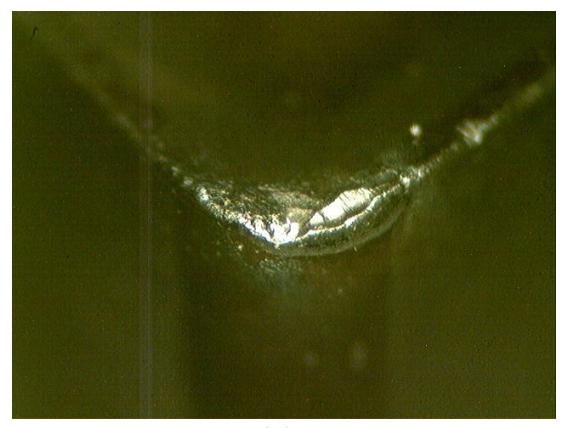

(c)

Fig. 2. Images of $\mathrm{ZrCN}$ coated insert after (a) $14 \mathrm{~min}$ (b) $26 \mathrm{~min}$ and (c) $31 \mathrm{~min}$

The gradual growth of $\mathrm{VBc}$ for multilayer coated insert indicates steady machining without any premature tool failure by chipping or fracturing. The machining time recorded to reach the wear limit for $\mathrm{ZrCN}$ coated carbide inserts was significantly longer nearly about $31 \mathrm{~min}$ to reach $0.3 \mathrm{~mm}$ of flank wear limit at $\mathrm{v}=90 \mathrm{~m} / \mathrm{min}, \mathrm{f}=0.05 \mathrm{~mm} / \mathrm{rev}$ and $\mathrm{d}=0.5 \mathrm{~mm}$. Thus the tool life of $\mathrm{ZrCN}$ coated carbide insert is found to be $31 \mathrm{~min}$ under the parametric conditions chosen. The three zones of wear have been observed i.e. initial wear followed by gradual or steady wear and finally rapid stage of wear. Abrasion was found to be the major mechanism of flank wear in hard turning within studied range. At the rake surface, crater wear occurred due to high pressure and temperature in hard turning and may be due to sliding of rough saw tooth chips on rake surface. The colour of chip changes from metallic to blue at the end of tool life. Hard turning generates very large amount of heat and high cutting temperature which reduces the tool life. The blue chips are evidences of higher cutting temperature during machining. With the increase in temperature, the rates of growth of flank wear increases.

Reduction of growth of wear using $\mathrm{ZrCN}$ coated carbide insert may be attributed due to its heat resistant property and effect of coatings acting as a thermal barrier (Aggarwala et al., 2008). This barrier prevents heat from entering the tool and hence most of the heat is removed by the chip. It clearly depicts the higher tool life for multilayer $\mathrm{ZrCN}$ coated carbide insert due to oxidation resistance and thermal barrier property of $\mathrm{Al}_{2} \mathrm{O}_{3}$ coating and adds wear resistance due to TiCN coating $\left(\mathrm{G}^{*} \mathrm{O}\right.$ 
KKAYA and Nalbant, 2006; Kudapaa et al., 1999). The results suggest that dry turning of hardened AISI 4340 steel could be performed using multilayer $\mathrm{ZrCN}$ coated carbide inserts due to their extended tool life and may be implemented in high speed applications.

\subsection{Cost analysis}

Utilizing the data of tool life, the total machining cost per part has been calculated in hard turning using multilayer $\mathrm{ZrCN}$ coated carbide inserts. The cost per piece has been calculated taking machining length (L) of $100 \mathrm{~mm}$ and diameter (D) of $40 \mathrm{~mm}$ respectively. The total cost of the machine and labor (x) is taken as Rs. 250 per hour $\left(4.16 \mathrm{~min}^{-1}\right)$. The mean value of a single cutting edge (y) is found to be Rs. 55 for multilayer-coated carbide inserts. Cost analysis for $\mathrm{ZrCN}$ coated carbide insert is furnished in Table 1.

\section{Table 1}

Machining cost per part in hard turning

Cutting conditions: $\mathrm{ZrCN}$ coated carbide $(\mathrm{v}=90 \mathrm{~m} / \mathrm{min}, \mathrm{f}=0.05 \mathrm{~mm} / \mathrm{rev}, \mathrm{d}=0.5 \mathrm{~mm}), \mathrm{L}=100 \mathrm{~mm}, \mathrm{D}$ $=40 \mathrm{~mm}, \mathrm{VBc}=0.3 \mathrm{~mm}$, Machining time $\left(\mathrm{T}_{\mathrm{c}}\right)=0.55 \mathrm{~min}$, Tool changing time $\left(\mathrm{T}_{\mathrm{d}}\right)=5 \mathrm{~min}, \mathrm{~W} / \mathrm{P}=$ AISI $4340(47 \pm 1$ HRC)

\begin{tabular}{lll}
\hline \multicolumn{1}{c}{ No } & \multicolumn{1}{c}{ Costs } & \multicolumn{1}{c}{ Multilayer ZrCN coated carbide } \\
\hline 1 & Value of machine and Operator $(\mathrm{x}), \mathrm{Rs} 250 / \mathrm{hr}$ & Rs 4.16 min $^{-1}$ \\
2 & Machining cost per part $\left(\mathrm{x} . \mathrm{T}_{\mathrm{c}}\right)$ & Rs 2.29 \\
3 & Tool life for single edge $(\mathrm{T})$ & $31 \mathrm{~min}$ \\
4 & Tool changing cost per part $\left[\mathrm{x} \mathrm{T}_{\mathrm{d}}\left(\mathrm{T}_{\mathrm{c}} / \mathrm{T}\right)\right]$ & Rs 0.37 \\
5 & Mean value of single cutting edge $(\mathrm{y})$ & Rs 55 \\
6 & Tool cost per part [y $\left.\left(\mathrm{T}_{\mathrm{c}} / \mathrm{T}\right)\right]$ & Rs 0.98 \\
7 & Total machining cost per part $(\mathrm{C}),(2+4+6)$ & Rs 3.64 \\
\hline
\end{tabular}

The total machining cost per part for multilayer $\mathrm{ZrCN}$ coated carbide insert is found to be only Rs. 3.64. It clearly depicts the economical benefits of hard turning with multilayer $\mathrm{ZrCN}$ coated carbide insert.

\section{Mathematical model}

A regression is performed on the data collected wherein the observed variable (response) is approximated based on a functional relationship between the estimated variable and one or more input variables (Montgomery, 1997). These relations are then modeled by using least square error fitting of the response surface. To test the fit of the model, the regression equation and determination coefficient $\left(\mathrm{R}^{2}\right)$ were calculated (Dilbag \& Rao, 2007) and acceptance was based on high to very high coefficients of correlation $\left(\mathrm{R}^{2}\right)$.

The second order response surface representing the flank wear $(\mathrm{VBc})$ can be expressed as a function of machining time $(\mathrm{T})$. The correlation between the relationship between the flank wear and machining time for $\mathrm{ZrCN}$ coated carbide insert has been expressed as follows:

$\mathrm{VBc}=-0.027123+0.011247 \mathrm{~T}-0.000014 \mathrm{~T}^{2} \quad \mathrm{R}^{2}=99 \%$

Analysis of variance has been performed to judge the significance of regression terms for adequacy of model. Result of ANOVA for the response function flank wear model is shown in Table 2. This analysis is carried out for a level of confidence of $95 \%$. Models are developed using uncoded units. If the P-value in ANOVA table is less than 0.05 then the models are said to be statically significant. 
Table 2

ANOVA for flank wear model

\begin{tabular}{llllllll}
\hline Source & DF & Seq SS & Adj SS & Adj MS & F & P & Remarks \\
\hline Regression & 2 & 0.08063 & 0.08063 & 0.040315 & 656.17 & 0.000 & Significant \\
Residual error & 5 & 0.000307 & 0.000307 & 0.000061 & & & \\
Total & 7 & 0.080938 & & & & & \\
\hline
\end{tabular}

Regression is statistically significant because $\mathrm{P}$ value is less than 0.05 . The coefficient of determination is particularly calculated in the analysis of response surface model and higher $\mathrm{R}^{2}$ (approaches to unity) shows the most significance of model developed. The model presented high determination coefficient $\left(\mathrm{R}^{2}=0.99\right.$ close to unity) explaining $99 \%$ of the variability in the response which indicates the goodness of fit for the model and high significance of the model. A check on the normal probability plot vs. residuals of second order model (Fig. 3) shows that the residuals lie reasonably close to a straight line implying that errors are distributed normally and giving support that the terms mentioned in the model are significant. The normal probability plot does not show any outliers at extremes but its standardized residual value was 2.15 i.e. less than 3 which should cause no concern.

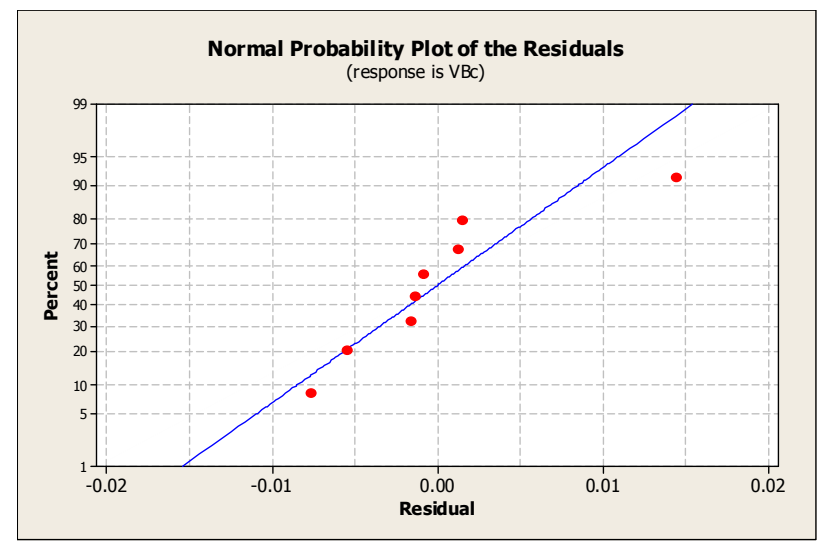

Fig. 3. Normal probability plot of the residuals

Also the predicted and experimental values are very close to each other. It shows the significance of model developed (Fig. 4). The residuals between the experiment and predicted value are very less being maximum error of $5.18 \%$ using $\mathrm{ZrCN}$ coated carbide insert and closely fitted.

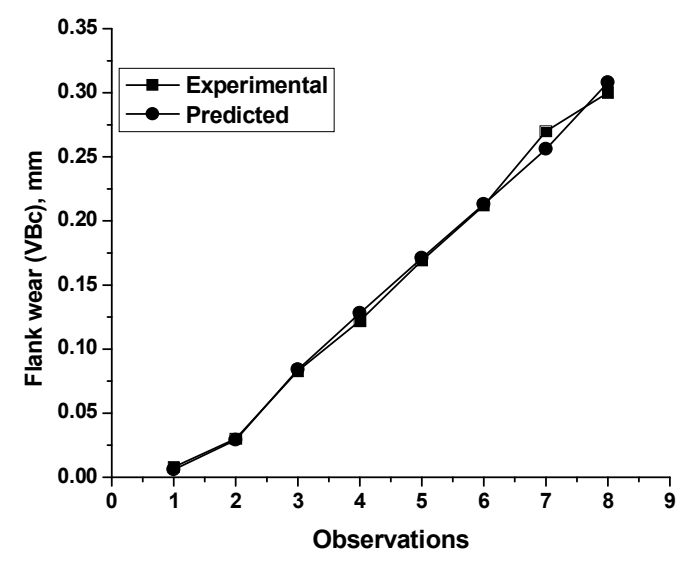

Fig.4. Experimental vs. predicted values of flank wear 
This analysis showed that the prediction model sufficiently explains the relationship between flank wear and the independent variables. Thus the regression model developed can be effectively used to predict the flank wear during machining hardened AISI 4340 steel with multilayer ZrCN coated carbide inserts.

\section{Conclusions}

The study focuses extensively on the aspects related to flank wear, tool life, economical feasibility and prediction model in hard turning using multilayer $\mathrm{ZrCN}$ coated carbide inserts. Therefore based from the findings of the research, following conclusions may be drawn.

1. Abrasion is found to be dominant wear mechanism in hard machining of AISI 4340 steel using multilayer coated carbide insert under dry environment.

2. The gradual growth of VBc for multilayer coated insert indicates steady machining without any premature tool failure by chipping or fracturing.

3. Tool life has been found to be 31 minute to reach the wear limit for $\mathrm{ZrCN}$ coated carbide inserts under parametric conditions such as cutting speed of $90 \mathrm{~m} / \mathrm{min}$, feed of $0.05 \mathrm{~mm} / \mathrm{rev}$ and depth of cut of $0.5 \mathrm{~mm}$.

4. It has been observed that, the $\mathrm{ZrCN}$ coated carbide insert gives a better and economical process of machining and yields only Rs.3.64 machining cost per part in hard turning.

5. The results suggest that dry turning of hardened AISI 4340 steel could be performed using multilayer $\mathrm{ZrCN}$ coated carbide cutting tools due to their extended tool life observed from experimentation.

6. Flank wear prediction model proposed is significant because of high determination coefficients $\left(\mathrm{R}^{2}=\right.$ 0.99 close to unity) and their $\mathrm{P}$ value is less than 0.05 .

7. The predicted flank wear value and experimental values are very close to each other. The residuals between the experiment and predicted value are very less and closely fitted showing significance of model developed.

8. Thus the regression model developed can be effectively used to predict the flank wear during machining hardened AISI 4340 steel using TiN/TiCN $/ \mathrm{Al}_{2} \mathrm{O}_{3} / \mathrm{ZrCN}$ multilayer coated carbide inserts.

\section{Acknowledgement}

The authors greatly appreciate and acknowledge the support and cooperation's rendered by CTTC, Bhubaneswar, India to carry out this research work.

\section{References}

Aggarwala, A., Singh, H., Kumar, P., \& Singh, M. (2008). Optimizing power consumption for CNC turned parts using response surface methodology and Taguchi's technique-A comparative analysis. Journal of Materials Processing Technology, 200, 373-384.

Gokkaya, H., \& NALBANT, M. (2006). The effects of cutting tool coating on the surface roughness of AISI 1015 steel depending on cutting parameters. Turkish Journal of Engineering Environmental Science, 30, 307-316.

Horng, J-T., Liu, N-M., \& Chiang, K. (2008). Investigating the machinability evaluation of Hadfield steel in the hard turning with $\mathrm{Al}_{2} \mathrm{O}_{3} / \mathrm{TiC}$ mixed ceramic tool based on the response surface methodology. Journal of Materials Processing Technology, 208 (1-3), 532-541.

Kudapaa, S., Narasimhan, K., Boppana, P., \& Russell, W.C. (1999). Characterization and properties of MTCVD TiCN and MTCVD ZrCN coatings. Surface and Coatings Technology, 120-121, 259-264. 
Lalwani, D.I., Mehta, N.K., \& Jain, P.K. (2008). Experimental investigations of cutting parameters influence on cutting forces and surface roughness in finish hard turning of MDN250 steel. Journal of Materials Processing Technology, 206 (1-3), 167-179.

More, A.S., Jiang, W., Brown, W.D., \& Malshe, A.P. (2006). Tool wear and machining performance of cBN-TiN coated carbide inserts and PCBN compact inserts in turning AISI 4340 hardened steel. Journal of Materials Processing Technology, 180, 253-262.

Montgomery, D.C. (1997). Design and Analysis of Experiments, $4^{\text {th }}$ ed. Wiley, New York.

Ozel, T., \& Karpat, Y. (2005). Predictive modeling of surface roughness and tool wear in hard turning using regression and neural networks. International Journal of Machine Tools \& Manufacture, 45, 467- 479 .

Sahin, Y. (2009). Comparison of tool life between ceramic and cubic boron nitride (CBN) cutting tools when machining hardened steels. Journal of Materials Processing Technology, 209, 3478-3489.

Sahin Y., \& Motorcu A.R. (2008). Surface roughness model in machining hardened steel with cubic boron nitride cutting tool. International Journal of Refractory Metals \& Hard Materials, 26, 84-90.

Sahoo, A.K., \& Sahoo, B. (2011). Mathematical modelling and multi-response optimisation using response surface methodology and grey based Taguchi method: an experimental investigation. International Journal of Experimental Design and Process Optimisation, 2(3), 221-242.

Sahoo, A.K., \& Sahoo, B. (2011). Surface roughness model and parametric optimization in finish turning using coated carbide insert: Response surface methodology and Taguchi approach. International Journal of Industrial Engineering Computations, 2, 819-830.

Singh, D., \& Rao, P. V. (2007). A surface roughness prediction model for hard turning process. The International Journal of Advanced Manufacturing Technology, 32(11-12), 1115-1124.

Tamizharasan, T., Selvaraj, T., \& Noorul Haq, A. (2006). Analysis of tool wear and surface finish in hard turning. International Journal of Advanced Manufacturing Technology, 28, 671-679.

Tönshoff, H., Wobker, H., \& Brandt, D. (1995). Hard Turning - Influences on the Workpiece Properties. Transactions of NAMRI/SME, Vol. XXIII, 215-220.

Tönshoff, H., Arendt, C., \& Ben Amor, R. (2000). Cutting of Hardened Steel. Annals of the CIRP, 49 (2), 547-565.

Yallese M.A., Rigal, J-F., Chaoui, K., \& Boulanouar, L. (2005). The effects of cutting conditions on mixed ceramic and cubic boron nitride tool wear and on surface roughness during machining of X200Cr12 steel (60 HRC). Proc. IMechE, Part B: J. Engineering Manufacture, 219, 35-55. 